\title{
The Analysis of Models of Formation of Tariff Policy on Services of Seaports
}

\section{Yu. A. Grigorieva}

Postgraduate Student, Assistant, Department of Transportations Organization and Management on Transport, State Sea University named after admiral F. F. Ushakov,

93, Lenin avenue, Novorossiysk, 353920 Russia

E-mail: y9788@mail.ru

Introduction. The most complex problem of regulation by port services is definition of methodological approaches to establishment of tariffs for services in transfer of freights in ports. The most part of existing methods of formation of tariffs for services of seaports or isn't suitable for practical realization in all ports of Russia, or actually brings much less benefits, than it was expected. One of the reasons of these tendencies is covered in lack of a uniform optimum method which promptly would cut expenses of seaports. In article value of formation of an effective method and tariff setting model in seaports is considered. Methods. Methods and tariff setting models in seaports represent various receptions and ways by means of which the enterprises of sea transport realize the purposes set by it and the chosen strategy of tariff setting. With a certain policy of tariff setting a certain model is inherent in each concrete enterprise, each of which possesses a number of positive and negative sides. It is possible to carry the following models to the most actual models: vertically integrated, model of independent producers of the port services, competitive model. The essence of each of the considered models of formation of a tariff gives the chance to identification of the most favorable conditions for development of uniform optimum model of formation of a tariff and method of calculation of cost of loading and unloading works. Results. Result of this work is the detailed analysis of the most actual models of formation of a tariff for services of seaports, identification of their positive and negative sides that is necessary for development of the uniform model, applicable Russia in all seaports.

Key words: tariff setting, tariff setting models, tariff setting methods.

\section{References}

1. Ivanov M. Ju. Metodicheskie osnovy razvitija i povyshenija konkurentosposobnosti rossijskih morskih portov. Diss. kand. ekon. nauk [Methodical bases of development and increase of competitiveness of the Russian seaports. Cand. econ. sci. diss.]. Novorossiysk, 2000. $40 \mathrm{p}$.

2. Orlovskaja T. N. Metody formirovanija i regulirovanija tarifnogo stilja avtotransportnogo predprijatija $v$ us- lovijah neustojchivoj konjunktury rynka. Diss. kand. ekon. nauk [Methods of formation and regulations of tariff style of the motor transportation enterprise in the conditions of unstable market condition. Cand. econ. sci. diss.]. St. Petersburg, 2005, 35 p.

3. Kent P. Je. Monitoring konkurentosposobnosti rynka portovyh uslug. Diss. kand. ekon. nauk [Monitoring of competitiveness of the market of port services. Cand. econ. sci. diss.]. NIPiVP, Luisianna University, USA, 1999. $39 \mathrm{p}$.

\section{ИНВЕСТИЦИОННЫЙ КЛИМАТ В РОССИИ И ЕГО ВЛИЯНИЕ НА ИНВЕСТИЦИОННУЮ ДЕЯТЕЛЬНОСТЬ КОМПАНИЙ ТЭК}

\section{И. Т. Садеков}

аспирант кафедры экономики и менеджмента,

Московский городской педагогический университет

E-mail: sadekov-ilyas@mail.ru

Введение. Более 10 лет Правительством Российской Федерации решается вопрос улучшения инвестиционного климата. Несмотря на это, он остается неблагоприятным, а рейтинг инвестиционной привлекательности Российской Федерации имеет негативную тенденцию. Теоретический анализ. Инвестиционная деятельность компаний ТЭК сопряжена с множеством проблем, связанных как с организацией и планированием данного процесса внутри организации, так и с взаимодействием всех внешних участников этой деятельности, включая и вопросы привлечения требуемого внешнего финансирования. Результаты. Меры по стимулированию прямых иностранных инвестиций не имеют практического характера и не решают основных проблем, таких как коррупция, неразвитая инфраструктура, отсутствие льготного налогообложения, политические риски. На этом фоне с учетом повышенных политических рисков в нефтегазовой отрасли количество проектов с участием иностранного капитала незначительно. Рейтинг инвестиционной привлекательности Российской Федерации имеет негативную тенденцию. Выводы. В настоящий момент предпринятые Правительством РФ действия по улучшению инвестиционного климата не приводят к желаемым результатам. Данная тенденция связана с отсутствием фактических изменений в сопровождении инвестиционных процессов, а также с отсутствием целостной программы стимулирования прямых иностранных инвестиций. Так как про- 
фессиональная среда реагирует только на конкретные факты, подтверждающие изменения, объемы прямых иностранных инвестиций существенно не изменились. В таких условиях особое значение приобретают государственные инвестиции, эффективность которых становится определяющим фактором развития экономики страны в текущем десятилетии.

Ключевые слова: инвестиционный климат, инвестиционная деятельность, государственная экономическая политика, топливно-энергетический комплекс.

\section{Введение}

В рамках формирования устойчивого развития экономики как на макро-, так и на микроуровне важную роль играет наличие постоянного притока инвестиций. Объем и структура привлекаемых в экономику инвестиционных ресурсов тесно связаны с уровнем доходности финансовых и капитальных активов, а также с уровнем инвестиционных рисков.

Инвестиционный климат государства представляет собой максимально обобщенную характеристику всех инвестиционных процессов, происходящих в стране, и является совокупностью различных - социально-экономических, природных, экологических, политических и других - условий, сложившихся в течение ряда лет и определяющих масштабы, объем и темпы привлечения инвестиций в основной капитал предприятий.

\section{Теоретический анализ}

Говоря о понятии «инвестиционный климат», важно отметить, что оно имеет комплексный характер и может рассматриваться как на макро-, так и на микроэкономическом уровне. Если на макроуровне данное понятие включает в себя показатели экономической, политической и социальной среды, то на микроуровне оно характеризуется качеством и количеством двусторонних отношений фирм-инвесторов и хозяйственных субъектов, а также их взаимоотношениями с органами государственной власти [1].

Согласно исследованию Doing Business 2012, составляемому ежегодно Всемирным банком и оценивающему условия ведения бизнеса в 183 странах, Россия занимает 120-е место по простоте осуществления предпринимательской деятельности [2].

По данным Минэкономразвития России, чистый отток капитала из страны в 2008-2011 гг. составил 308 млрд долл. Данный показатель обусловлен, в частности, инвестициями российских компаний за рубеж и снижением активности инвесторов в связи с общей неопределенностью на мировых рынках и ситуацией в Европе.

В 2010 г. улучшение инвестиционного климата было определено как самостоятельное направление деятельности Министерства экономического развития России, и за два про- шедших года были упрощены процедуры в сфере строительства и миграционной политики, существенно снижена стоимость подключения новых инвестиционных проектов к электросетям и инженерно-коммуникационной инфраструктуре, приняты законы, направленные на совершенствование таможенного администрирования, а также либерализацию контроля за иностранными инвестициями, и уголовного законодательства в экономической сфере, запущен механизм уполномоченных по инвестициям на федеральном и региональном уровнях, удалось добиться увеличения объема инвестиций международных институтов развития в приоритетные для российской стороны отрасли экономики и многое другое.

Только за счет реализации этих мер в 20102011 гг. Россия поднялась на 4-ю позиции в рейтинге Doing Business (со 124-го места до 120-го), а также вошла в число 25 стран по прогрессу в улучшении инвестиционного климата.

В 2008-2011 гг. в Россию поступило 206,7 млрд долл. США прямых иностранных инвестиций (ПИИ). По итогам 2011 г., по оценке Банка России, объем ПИИ составил 51,9 млрд долл. (19,9\%-ный рост к 2010 г.) [2].

По данным опроса Merril Lynch, проведенного среди международных управляющих инвестиционных фондов, Россия заняла первое место по инвестиционной привлекательности среди стран БРИКС.

В рейтинге самых дешевых стран для ведения бизнеса в 2012 г. Россия заняла четвертое место из 19 развитых и развивающихся стран, уступая лишь Индии, Китаю и Мексике, по версии КPMG.

Наряду с этим Россия занимает 60-е место среди 187 исследуемых стран в рейтинге страновых инвестиционных рисков, присвоенных журналом Euromoney в 2012 г. [2].

Главная задача государственной политики поддержки инвестиций, сформулированная Президентом России В. В. Путиным в ежегодном Послании Федеральному собранию, заключается в улучшении экономических условий для развития инвестиционной деятельности, а также в создании «инвестиционных карт», для информирования иностранных инвесторов об имеющихся в разработке проектах и степени данных проектов со стороны государства [3]. Привлекательность инвестиционной среды определяется, прежде всего, условиями налоговой, амортизационной, финансово-кредитной политики государства. При этом для потенциальных инвесторов имеют значение не только действующие в конкретный момент условия, но и ожидаемые перспективы их развития, степень стабильности политической и экономической ситуации в стране и другие факторы. 
Важно понимать, что для инвесторов при анализе политической составляющей инвестиционной привлекательности страны решающее значение имеет позиция государства в отношении иностранных инвестиций:

- вероятность национализации иностранного имущества;

- участие страны в системах международных договоров по различным вопросам;

- прочность государственных институтов;

- преемственность политической власти;

- степень государственного вмешательства в экономику и т.д.

Одним из важнейших условий обеспечения экономического роста служит сбалансированная инвестиционная политика государства, стратегически нацеленная на поддержание экономической и политической стабильности в долгосрочной перспективе [1].

Учитывая значение инвестиций для экономики страны в целом, стоит отдельно отметить важность привлечении инвестиций в топливноэнергетическую отрасль экономики. Топливноэнергетический комплекс (ТЭК) обеспечивает треть валового внутреннего продукта, формирует общие экономические параметры, принципиально влияющие на динамику экономического развития.

Рассматривая проблему переориентации производства на высокотехнологичную продукцию с высокой добавленной стоимостью, необходимо определить те отрасли экономики, которые смогли бы поднять волну экономического роста и распространить ее далее на всю социально-экономическую систему, приведя к новому качеству экономического роста. Поэтому так актуален сегодня вопрос инвестирования ТЭК, который не только является базой для вывода страны на путь устойчивого развития, но и определяет геополитическое влияние России.

Топливно-энергетический комплекс РФ представляет собой сложную систему - совокупность производств, процессов, материальных устройств по добыче топливно-энергетических ресурсов (ТЭР), их преобразованию, транспортировке, распределению и потреблению как первичных ТЭР, так и преобразованных видов энергоносителей.

Инвестиционная деятельность компаний ТЭК сопряжена с множеством проблем, связанных как с организацией и планированием данного процесса внутри организации, так и с взаимодействием всех внешних участников этой деятельности, включая и вопросы привлечения требуемого внешнего финансирования. Именно длительность подготовки инвестиционных проектов - от концептуального анализа до внедрения - является основным вопросом организации инвестиционного процесса. Сложности связаны с такими факторами, как высокая потребность в инвестиционных ресурсах уже на этапах планирования, вовлечение в работу большого количества персонала, привлечение к работе различных третьих сторон и риски неопределенностей с окончательной стоимостью проекта изза отсутствия выбора конкретных технологий и постоянной инфляции [4, с. 27-29].

На данный момент в отрасли существует ряд проблем, не позволяющих ТЭК соответствовать требованиям времени, ключевой из которых является высокая энергоемкость российского ВВП. В рамках политики по снижению энергоемкости российской экономики в 2008 г. был подписан Указ Президента РФ от 04.06.2008 г. № 889 «О некоторых мерах по повышению энергетической и экологической эффективности российской экономики». Была поставлена задача по снижению энергоемкости ВВП к 2020 г. не менее чем на 40\% по сравнению с 2007 г. [5].

Несмотря на это, отчасти в связи с мировым экономическим кризисом, энергоемкость российского ВВП и по сей день остается достаточно высокой.

Степень износа основных фондов в добывающей промышленности составила в 2010 г. $51,1 \%$ [6, с. 343].

Износ основных фондов не только влечет за собой отставание в эффективности производства, но и увеличивает риск аварий в энергетическом секторе. Наметившийся энергодефицит ограничивает промышленный рост и решение приоритетных задач в социальной сфере. Дефицит производства усугубляется неэффективностью генерации, низким КПД действующих установок. Нарастает процесс физического и морального старения генерирующего и электросетевого оборудования. Это вводит энергетику в зону повышенного риска технологических отказов и аварий.

Основными факторами, которые необходимо учитывать при формировании инвестиционной политики в комплексе, являются:

- высокая степень износа ОПФ;

- несоответствие ценовых пропорций на взаимозаменяемые энергоресурсы;

- отставание производственного и научно-технического потенциала ТЭК от мирового уровня;

- высокая энергоемкость экономики;

- высокая зависимость нефтегазового комплекса от конъюнктуры мирового энергетического рынка;

- ухудшение качественной структуры запасов углеводородов;

- отсутствие оптимальной рыночной инфраструктуры и цивилизованного, конкурентного энергетического рынка; 
- сокращение объемов геологоразведочных работ, что затрудняет сохранение высоких темпов добычи нефти и газа в будущем.

Инвестиции в топливно-энергетический комплекс, помимо развития самой отрасли, вызовут мультипликационный эффект и отразятся на повышении спроса на высокотехнологичные буровые установки, установки по обработке и хранению сырья, трубную продукцию, повлекут развитие транспортной сети и пр., стимулируя, таким образом, подъем машиностроения. Первоначальный толчок от инвестиций в топливноэнергетический комплекс своей «третьей волной» захватит смежные отрасли машиностроения (металлургию, химию и нефтехимию), порождая новые инвестиции, новые рабочие места, увеличивая в целом национальный доход, и, таким образом, перейдет на всю экономику в целом, обеспечивая переход на новый технологический уклад, качественный экономический рост.

Таким образом, инвестиционная политика в ТЭК должна соответствовать стратегии экономического развития страны, обеспечивая восстановление научно-производственного потенциала и его дальнейший рост на основе активизации конкурентных преимуществ российской экономики.

Топливно-энергетический комплекс России на данный момент обладает высоким потенциалом инвестиционной привлекательности [4, с. 27-29]. Как следует из доклада министра энергетики России Александра Новака на 49-й Мюнхенской конференции по безопасности «Геополитические изменения в контексте американской нефтегазовой революции», Российское правительство планирует специальные меры по повышению привлекательности инвестиций в ТЭК и отдельно подчеркивает значимость данной отрасли для развития экономики страны в целом:

«Россия является крупнейшей энергодержавой и занимает, соответственно, первое и второе место в мире по объемам добычи нефти и газа. По итогам 2012 г. объем национальной добычи нефтяного сырья увеличился по сравнению с 2011 г. на 1,3\% и составил в абсолютном выражении 518 млн т, установив новый максимальный уровень в истории России. Добыча природного газа в 2012 г. составила 654,4 млрд куб. м.

Во-первых, в своей политике мы исходим из принципа реалистичности. Мы внимательно отслеживаем изменения, происходящие на мировом энергетическом рынке, включая изменения в энергобалансе, инфраструктуре, маршрутах поставок и технологическом развитии отрасли.

Основным приоритетом роста экспорта на перспективу мы видим рост потребления энергоресурсов в странах Азиатско-Тихоокеанского региона, и прежде всего в Китае.

Мы будем ускоренно инвестировать в развитие ресурсной базы и реализацию инфраструк- турных проектов, которые позволят нам удовлетворять потребности этих рынков в углеводородном сырье. Создание стимулов для работы в восточном направлении является нашим стратегическим приоритетом на десятилетия вперед.

Например, мы стимулируем добычу нефти и газа в восточных регионах страны, активно строим нефтегазотранспортную инфраструктуру в восточном направлении, развиваем СПГ-проекты» [7].

Также Правительство РФ в 2012 г. обещало ряд послаблений для нефтяной отрасли, которые должны стать стимулом для разработки сложных и труднодоступных месторождений. По мнению экспертов, без этого отрасль уже в скором времени столкнется с падением добычи из-за истощения действующих месторождений. Правда, по большинству инициатив дальше обещаний дело пока не пошло.

В конце сентября 2012 г. Правительство РФ приняло решение о расширении налоговых льгот для добычи нефти в Восточной Сибири: каникулы по НДПИ будут продлены до 1 января 2022 г., а экспортная пошлина для новых месторождений этого региона будет снижена почти вдвое. Еще одно решение принято по месторождениям с трудноизвлекаемой нефтью - Президент РФ Владимир Путин в начале декабря 2012 г. подписал закон о применении в отношении такой нефти пониженной ставки вывозной таможенной пошлины в размере $10 \%$ от обычной.

Минэнерго также ведет работу над единой методикой предоставления льгот для нефтяных месторождений, реализованной в новой редакции закона о таможенном тарифе (№ 239-Ф3 от 03 декабря 2012 г.), в который включена методология предоставления льгот по экспортным ставкам для месторождений нефти. Власти РФ продолжили в 2012 г. обсуждение новой системы налогообложения российского шельфа, но до конкретных решений дело опять не дошло.

Несмотря на принимаемые государством меры по улучшению инвестиционного климата в стране, экономику России трудно назвать привлекательной для иностранных инвестиций. Об этом свидетельствуют многочисленные рейтинги, в которых Россия оценивается как страна с неблагоприятным инвестиционным климатом. Согласно данным Национального рейтингового агентства, представленным в Индексном рейтинге инвестиционной привлекательности стран, наша страна занимает лишь 116-е место по итогам 2011 г. Если рассмотреть динамику занимаемых Россией позиций в промежутке с 2008 по 2011 г., то рейтинг инвестиционной привлекательности страны увеличился с 137 до 116 (данные 2008 и 2011 гг. соответственно). Представленная динамика положительна, но, тем не менее, недостаточна для реализации 
поставленных Правительством РФ целей сохранения докризисных темпов роста, привлечения иностранных инвестиций и модернизации экономики. На данный момент суммарный объем инвестиций не удовлетворяет реальных потребностей российской экономики в средствах.

К 2012 г. фактически исчерпан потенциал экстенсивного роста нефтяной отрасли России: страна впервые вступает в период, когда показатели добычи и экспорта нефти не будут расти. Проблема сырьевой зависимости российской экономики сформировала комплекс рисков, результирующей которых является невозможность выполнения социальных, оборонных и экспортных обязательств России при темпах роста экономики ниже 4-5\%. В этой связи устойчивость развития нефтяной отрасли России и экономики в целом в перспективе до 2020 г. определяют следующие взаимосвязанные факторы:

- формирование умеренного спроса на нефть на мировом рынке и замедление роста цен;

- ухудшение структуры запасов нефти России при низких показателях эффективности проектов добычи и переработки;

- освоение запасов удаленных регионов и шельфа при соответствующей переработке попутного углеводородного сырья;

- дисбаланс структуры производства нефтепродуктов при неэффективном регулировании их производства и экспорта;

- необходимость ускорения проектов модернизации мощностей в сегменте переработки нефти.
Влияние данных факторов на конъюнктуру рынка ТЭР обусловило высокую актуальность вопроса мониторинга и оценки инвестиционной активности в ТЭК, перспектив и темпов реализации инвестиционных проектов в добыче, транспортировке и переработке углеводородов.

Стратегическими задачами развития нефтяной отрасли Российской Федерации являются поддержание уровня добычи нефти, обеспечивающего максимальный и устойчивый экономический эффект, развитие нефтепереработки и транспортной инфраструктуры для обеспечения внутренней и экспортной потребности в нефти и нефтепродуктах. Для успешного выполнения поставленных задач в рамках исчерпанного потенциала экстенсивного роста особое значение приобретает привлечение иностранных инвестиций [7, с. 7].

\section{Результаты}

Как отмечает профессиональное сообщество, за последние годы основные проблемы инвестиционного климата в России остались нерешенными, что, в свою очередь, негативно отразилось на интересе иностранного капитала к российскому рынку. Ожидания зарубежного бизнеса в либерализации российского рынка также не оправдались, что в реальном выражении привело к снижению количества инвестиционных проектов в 2011 г. Данная динамика продемонстрирована на диаграмме (рисунок).

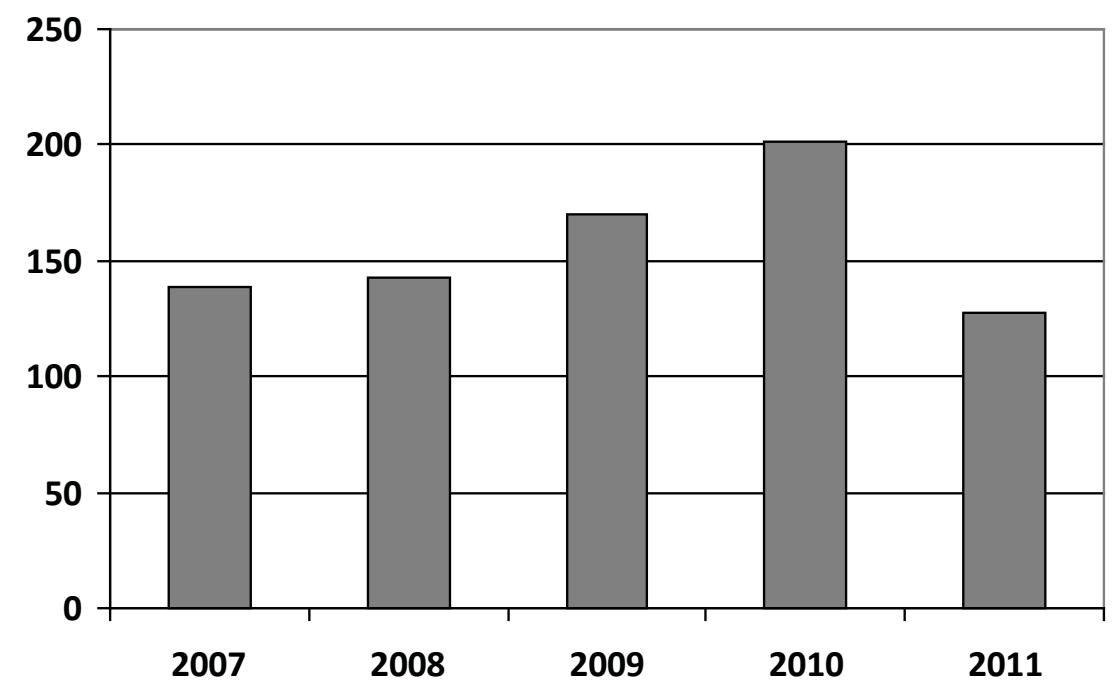

Количество инвестиционных проектов с привлечением прямых иностранных инвестиций $[8$, с. 23$]$

Характерным свидетельством потери интереса иностранных инвесторов к российскому топливно-энергетическому комплексу на уровне прямых вложений являются сведения, пред- ставленные в статье журнала «Эксперт» «Все инвестиционные проекты на территории России (с 1 ноября 2011 года по 31 января 2012 года)», в которой собраны основные инвестиционные 
проекты 2012 г. и классифицированы по типу инвестора. Опубликованные данные демонстри- руют, что ни в одном проекте 2012 г. в сфере ТЭК не участвовал иностранный капитал (таблица).

Инвестиционные проекты в сфере ТЭК [9]

\begin{tabular}{|l|c|l|l|l|}
\hline \multicolumn{1}{|c|}{ Инвестпрект } & $\begin{array}{c}\text { Объем } \\
\text { инвестиций } \\
\text { (млн долл. }\end{array}$ & \multicolumn{1}{|c|}{ Регион } & Собственник & Тип инвестора \\
\hline Нефтепровод & 3300 & $\begin{array}{l}\text { Грянская, } \\
\text { Тволенская, } \\
\text { Новгородская, } \\
\text { Ленинградская } \\
\text { области }\end{array}$ & федеральный \\
\hline $\begin{array}{l}\text { Нефтеперерабатывающий } \\
\text { завод }\end{array}$ & 2300 & Краснодарский край & Роснефть & федеральный \\
\hline Выставочный центр & 1000 & Санкт-Петербург & Газпром & федеральный \\
\hline ТЭц & 1000 & Санкт-Петербург & $\begin{array}{l}\text { Правительство } \\
\text { Санкт-Петербурга }\end{array}$ & региональный \\
\hline Энергоблок & 500 & Москва & федеральный \\
\hline ЛЭП и электроподстанция & 260 & Курганская область & ФСК ЕЭС & федеральный \\
\hline Электроподстанция & 253 & Санкт-Петербург & ФСК ЕЭС & федеральный \\
\hline ЛЭП & 203 & Свердловская область & ФСК ЕЭС & федеральный \\
\hline Электроподстанция & 183 & Кемеровская область & ФСК ЕЭС & федеральный \\
\hline Электроподстанция & 100 & Краснодарский край & ФСК ЕЭС & федеральный \\
\hline Малая ГЭС & 13 & Ставропольский край & Русгидро & федеральный \\
\hline
\end{tabular}

Приведенные выше данные показывают влияние инвестиционного климата на инвестиционную деятельность компаний ТЭК в сфере привлечения иностранного капитала.

\section{Выводы}

Важно отметить, что профессиональная среда реагирует лишь на результаты принятых Правительством РФ мер. Пока меры по улучшению инвестиционного климата не приведут к решению основных проблем при осуществлении коммерческой деятельности и устранению опасений инвесторов, привлекательность российской промышленности и экономики в целом останется на том же недопустимо низком уровне.

На этом фоне особое значение приобретают государственные инвестиции. От того, насколько эффективно будут использованы государственные инвестиции, зависит развитие экономики страны.

\section{Список литературы}

1. Хисматуллин И. Р. Особенности инвестиционного климата России на современном этапе // Современные исследования социальных проблем. 2012. № 9. C. 5-6.

2. Справка об инвестициях // Министерство экономического развития РФ, 2012. URL: http://www.economy. gov.ru/wps/wcm/connect/economylib4/mer/activity/ sections/investmentpolicy/doc20121029 08 (дата обращения: 09.02.2013).

3. Послание Президента Федеральному Собранию // Рос. газ. 2012. № 287 (5960).

4. Робертус В. В. Инвестиционная деятельность топливно-энергетического комплекса как фактор обеспечения экономической безопасности Российской Федерации : дис. ... канд. экон. наук. М., 2010. $180 \mathrm{c}$.

5. О некоторых мерах по повышению энергетической и экологической эффективности российской экономики : указ Президента РФ от 04.06.2008 № 889. URL: http://www.kremlin.ru/news/313 (дата обращения: 09.02.2013).

6. Российский статистический ежегодник / Федеральная служба государственной статистики. М., 2012. 786 с.

7. Нефтяная и нефтеперерабатывающая промышленность России 2012-2020 гг. Инвестиционные проекты и описание компаний / Информационное агентство «Infoline». M., 2012. 720 c.

8. Прямые иностранные инвестиции в российскую экономику в 2011 году : увеличение масштаба проектов // Потенциал роста, «Эрнст энд Янг (СНГ) Б.В.». М., 2012. 52 c.

9. Все инвестиционные проекты на территории России (с 1 ноября 2011 года по 31 января 2012 года) // Эксперт. 2012. № 16(799). URL: http://expert.ru/ratings/ vse-investitsionnyie-proektyi-na-territorii-rossii-s1-noyabrya-2011-goda-po-31-yanvarya-2012-goda/ (дата обращения: 14.02.2013). 


\title{
The Investment Climate in Russia and Its Impact on the Investment Activities of Companies of the Fuel and Energy Industry
}

\author{
I. T. Sadekov \\ Postgraduate Student, Department of Economics and Management, \\ Moscow City Pedagogical University, \\ 4, 2nd Agricultural passage, Moscow, 129226 Russia \\ E-mail: sadekov-ilyas@mail.ru
}

Purpose. More than 10 years the Government of the Russian Federation has addressed the issue of improving the investment climate. Inspite of it, the investment climate in the country remains poor, and the rating of investment attractiveness of the Russian Federation has a negative trend. Theoretical analysis. Investment activity of energy companies is associated with many problems associated with both the organization and planning of the process within the organization and the interaction with all external involved actors, including the issues of required attracting external funding. Results. Measures to encourage foreign direct investment do not have a practical nature and do not solve the basic problems: corruption, poor infrastructure, lack of tax benefits, and political risks. Against this background, taking into account the increased political risk in oil and gas projects with the participation of foreign capital is negligible. Rating of investment attractiveness of the Russian Federation has a negative trend. Conclusions. At the moment, the measures taken by the Russian government to improve the investment climate do not lead to the desired results. This trend is related to the lack of actual change in support of investment processes, as well as the lack of an integrated program to stimulate foreign direct investment. As the professional environment responds only the specific facts supporting the changes, foreign direct investment has not changed. Under such conditions the public investment are particularly important. The effectiveness of public investment becomes the determining factor in the development of the economy in the current decade. Key words: investment climate, investment development, government economic policy, fuel and energy industry.

\section{References}

1. Hismatullin I. R. Osobennosti investitsionnogo klimata Rossii na sovremennom etape [Features of the investment climate in Russia at the present stage]. Sovremennye issledovanija sotsialnyh problem [Modern studies of social problems], 2012, no. 9, pp. 5-6.

2. Spravka ob investitsiyakh (Statement of Investments). Ministerstvo ekonomicheskogo razvitiya $R F$ (The Ministry of Economic Development Russian Federation, 2012). Available at: http://www.economy.gov.ru/ $\mathrm{wps} / \mathrm{wcm} /$ connect/economylib4/mer/activity/sections/ investmentpolicy/doc20121029_08 (accessed 09 February 2013).

3. Poslanie Prezidenta Federalnomu Sobraniyu [President's speech Russian Federal Assembly]. Rossiyskaya Gazeta [Russian newspaper], 2012, no. 287(5960).

4. Robertus V. V. Investitsionnaya deyatelnost toplivnoenergeticheskogo kompleksa kak faktor obespecheniya ekonomicheskoy bezopasnosti Rossiyskoy Federatsii. Dis. kand. ekon. nauk [Investment activity of the fuel and energy industry as a factor in ensuring economic security of the Russian Federation. Cand. econ. sci. diss.]. Moscow, 2010. 180 p. (in Russian).

5. O nekotorykh merakh po povysheniyu energeticheskoy $i$ ekologicheskoy effektivnosti rossiyskoy ekonomiki. Ukaz Prezidenta RF ot 04.06.2008 № 889 (On some measures to improve the energy and environmental efficiency of the Russian economy. RF Presidential Decree of 04.06.2008 № 889). Available at: http://www.kremlin. ru/news/313 (accessed 09 February 2013).

6. Rossiyskiy statisticheskiy ezhegodnik. Federalnaya sluzhba gosudarstvennoy statistiki [Statistical Yearbook of Russia. Federal State Statistics Service]. Moscow, 2012. $786 \mathrm{p}$.

7. Neftyanaya i neftepererabatyvayushchaya promyshlennost Rossii 2012-2020 gg. Investitsionnye proekty $i$ opisanie kompaniy. Informatsionnoe agentstvo Infoline [Petroleum and petroleum-refining industry 20122020 of Russia. Investment projects and company descriptions. News agency Infoline]. Moscow, 2012. 720 p.

8. Pryamye inostrannye investitsii v rossiyskuyu ekonomiku v 2011 godu: uvelichenie masshtaba proektov [Foreign direct investment to the Russian economy in 2011: an increase in the scale of projects]. Potentsial rosta, Ernst end Yang (SNG) B.V. [Upside, Ernst \& Young (CIS) B.V.]. Moscow, 2012. 52 p.

9. Vse investitsionnye proekty na territorii Rossii (s 1 noyabrya 2011 goda po 31 yanvarya 2012 goda) (All investment projects on the territory of Russia (from 1 November 2011 to 31 January 2012)). Ekspert (Expert), 2012, no. 16(799). Available at: http://www.expert.ru/ ratings/vse-investitsionnyie-proektyi-na-territorii-rossii-s-1-noyabrya-2011-goda-po-31-yanvarya-2012-goda/ (accessed 14 February 2013). 